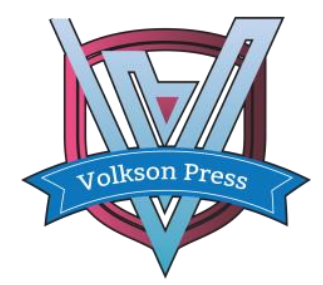

Contents List available at VOLKSON PRESS Clean Water,Air\&Soil(CleanWAS) DOI : http://doi.org/10.26480/cleanwas.01.2017.15.16

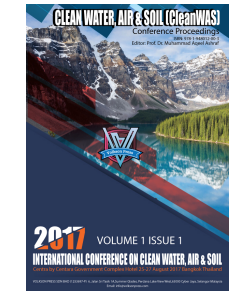

\title{
Hazards of haze
}

\author{
Xu Ruishan* \\ Department of rehabilitation, Wuwei people's Hospital, Wuwei City Gansu Province, China \\ *Corresponding Author: xuruishan_ww@163.com
}

This is an open access article distributed under the Creative Commons Attribution License, which permits unrestricted use, distribution, and reproduction in any medium, provided the original work is properly cited

\section{ARTICLE DETAILS}

\section{Article History:}

Received 02 october 2017

Accepted 06 october 2017

Available online 11 october 2017

Keywords:

haze, ecological environment,

health, economy

\section{ABSTRACT}

Haze days in China has occurred frequently in recent years. Severe haze has become the focus of environmental governance. The impact of haze to human beings involves in many aspects, and it not only affects the ecological environment and human health, but also causes a huge loss of social and economic development.

\section{Introduction}

Haze is basically formed by the merging of two weather phenomena "fog" and "haze", which is the result of the interaction of climatic and environmental elements. The main components of haze are sulfur dioxide, nitrogen oxides and respirable particulate matter, in which sulfur dioxide and nitrogen oxides are gaseous pollutants, while respirable particulate matter is the main reason for increasing fog haze pollution. PM2.5 (also known as particulate matter) is defined as particulate matter with a diameter of 2.5 micrometers or less in the atmosphere. Foreign scholars believe that the PM2.5 components are complex and its main components are aluminum, carbon, nickel, titanium, etc. Traffic emissions are the main source of carbon pollution, and the fuel produced by the pollutants is the main source of nickel, and road dust is the main source of aluminum element, and the crust material is the initial material that produces the titanium element.[1]

With the deterioration of air quality and the increase of haze weather, haze has become one of the important problems of environmental pollution in China. At the same time, the impact of haze weather to human beings involves in many aspects. It not only affects the quality of the ecological environment, but also cause harm to human health. And the frequent occurrence of haze also causes great losses to the social economy.

\section{The Harm of Haze to Ecological Environment}

Ecological environment is a dynamic system formed naturally, with a certain self-repair function. When the improper artificial activities cause ecological imbalance and destruction, the system will be confronted with multiple crises, such as environmental pollution, ecological imbalance, structural and functional change. The mass concentration of PM2.5 is negatively correlated with atmospheric visibility, which indicates that the increase of PM2.5 concentration in the atmosphere is the main reason for the decrease of visibility and the formation of haze. PM2.5 has the feature of small size, large area, strong activity, easy to attach with toxic and harmful substances(such as heavy metals, microbial, etc). The residence time of PM2.5 in the atmosphere is long and the transportation distance is far, so it has a great influence on the quality of the ecological environment

\section{The Harm of Haze to Human Health}

The impact of haze on human health mainly includes the damage of respiratory system, urogenital system, eye, nose, throat, emotional psychology, diabetes, brain tissue and so on.

\subsection{Respiratory System}

The respiratory system is first affected by fog and haze weather, Aerosols in the atmosphere move into the bronchial tube and bronchioles with the respiratory movements, and stay in the alveolar eventually, causing damage to the trachea, bronchi and lungs, inducing asthma, causing bronchitis and lung infections, aggravating the illness of chronic bronchitis and emphysema and other chronic respiratory diseases. In addition, longterm living in the fog and haze environment will increase the incidence of lung cancer. The American Cancer Society pointed out that PM2.5 was positively associated with lung cancer mortality.[2]

\subsection{Urogenital System}

The hazardous effects of haze on the urogenital system is mainly manifested in conception and fetal growth, including low fertility, premature birth, and neonatal weight loss. Study of Yale University has shown that some of the components of PM2.5 may be associated with low birth weight of neonates in the northeastern United States and the central area of Atlantic, while low birth weight may increase the risk of cardiovascular events and death.[3] Coincidentally, Harvard University scholars have come to a similar conclusion that PM2.5 is associated with premature birth and low birth weight. For example, throughout the pregnancy, PM2.5 in the air increased by $10 \mathrm{ug} / \mathrm{m} 3$, the birth weight of newborns decreased by 13.8 grams, and the preterm birth rate was $1.06 \%$ .[4]

\subsection{Cardiovascular System}

It is now widely believed that PM2.5 is associated with acute cardiovascular events, including heart ischemia, myocardial infarction, and stroke. Inhalation of PM2.5 can accelerate the deposition of atherosclerotic plaques, causing vascular inflammation and atherosclerosis, leading to cardiovascular disease and other cardiovascular problems.[5] Study has confirmed that with an increase of $10 \mathrm{ug} / \mathrm{m} 3$ of PM2.5 in the air, the mortality rate of patients with ischemic heart disease increased by $31 \%$, and the mortality of other cardiovascular events increased by $15 \%$ to $16 \%$.[6] In addition, PM2.5 increases the chance of acute respiratory infections in patients with cardiovascular disease, thereby increasing the burden on the heart, and its severe consequences can lead to heart failure.

\subsection{Eye, Nose and Throat}

PM2.5 irritates eye, nose and throat. It can cause the eye produce dry, itching, photophobia, tears and other symptoms, leading to the occurrence 
of conjunctivitis. nasal mucosa stimulation can increase the recurrence of allergic rhinitis, nasal itching, sneezing and other symptoms, the throat can appear dry throat, itching throat, sore throat and other symptoms.

\subsection{Emotional Psychology}

The haze weather can lead to negative emotions, and the mechanism may be associated with the increasing melatonin secretion of pineal gland. The increase of melatonin wil reduce the secretion of thyroxine and epinephrine, which leads to depression, low mood and easy to fatigue. Studies have shown that $67 \%$ of the residents in the haze areas felt "unhappy" and $70 \%$ of the population felt "less happy".[7]

\subsection{Other Aspects}

The haze weather is associated with the increasing incidence of diabetes: Portuguese scholars think that Portugal diabetes surge during 2004 2005 may be associated with PM2.5.[8] The haze weather is also associated with hospitalization rate: a Madrid study has shown that PM2.5 is the only pollutant that has statistical correlation with the hospitalization rate.[9] PM2.5 is associated with brain tissue damage too, it can affect brain tissue through pulmonary gas exchange and migration to brain tissue, the pathological change of brain tissue is like that of patients with Alzheimer's disease.

\section{The Social and Economic Losses caused by Harm}

The social and economic losses caused by fog and haze are multifaceted, mainly including traffic losses, health costs and damage to agricultural production. Traffic losses include flight delays, traffic congestion, traffic accidents and highway closure due to weather conditions. Health costs are mainly economic losses for hospital outpatient or emergency care. According to the statistics, due to PM2.5 pollution, the number of premature deaths was 7770 people and the economic loss amounted to 6.17 billion yuan in Beijing, Shanghai, Guangzhou and Xi'an, in 2010.[10] While in January 2013, the direct economic losses of national transportation and health caused by haze events were estimated conservatively about 23 billion yuan, of which the cost of emergency/ outpatient loss were about 22.6 billion yuan which account for $98 \%$ of the total loss.[11] At the same time, the risk of acute health damage on the 10 $\sim 15$ high concentrations of PM2.5 exposure in Beijing residents was evaluated and the economic loss of human health damage was estimated. The results showed that short-term high concentration of PM2.5 pollution on the population health risk was higher. Short-term high concentration of PM2.5 pollution caused about 201 cases of premature death, 1056 cases of respiratory disease hospitalized, 545 cases of cardiovascular disease hospitalized, 7094 cases of pediatrics outpatient, 16881 cases of medical outpatient department, 10132 cases of acute bronchitis, and 7643 cases of asthma. The related health and economic losses were up to 489 million yuan.[12] The data has shown that the loss of health would save the economic loss about 16.81 to 22.69 billion yuan if the PM2.5 could be effectively controlled and achieved to the level 2 or 1 of new environmental quality control standards in Beijing.[13] The impact of fog and haze on agricultural production mainly include the yield of crops due to the photosynthesis of crops weakened and the time of illumination reduced.

\section{Conclusion}

The harm and influence of haze are manifold. It not only affects and endangers the health of human beings, but also affects and hinders the sound development of the ecological environment and social economy. Therefore, we should take effective measures to strengthen the governance of haze. Haze governance is a complex system engineering, it is not easy to solve the problem within a short period of time, in order to solve this problem, we need the government, enterprises, media, social organizations and the public and other aspects involved in solving. Through a series of haze governance measures, for example, to improve the ecological environment, promote green travel, low-carbon life, rational development and utilization of natural resources, strengthen the legal protection, to promote environmental protection and cultural construction etc..

\section{References}

[1] Bell ML, Dominici F, Ebisu K, Zeger SL, Samet JM. Spatial and temporal variation in PM2.5 chemical composition in the United States for health effects studies[J]. Environ Health Perspect, 2007, 115: 989-995.

[2] Krewski D, Jerrett M, Burnett RT, Ma R, Hughes, E, et al. Extended follow-up and spatial analysis of the American Cancer Society study linking particulate air pollution and mortality[J]. Res Rep Health Eff Inst, 2009, 140, 5-114, discussion 115-136.

[3] Ebisu K, Bell ML. Airborne PM2.5 Chemical Components and Low Birth Weight in the Northeastern and Mid-Atlantic Regions of the United States [J]. Environ Health Perspect, 2012, 120(12): 1746-1752.

[4] Kloog Melly SJ, Ridgway WL, Coull BA, Schwartz J. Using new satellite based exposure methods to study the association between pregnancy pm2.5 exposure, premature birth and birth weight in Massachusetts[J]. Environ Health, 2012, 11(10): 40.

[5] Lu Y. A Good Environment Promotes National Happiness [N]. China Social Science Daily, 2013, 421: 1-2.

[6] Tillett T. Hearts over Time-Cardiovascular Mortality Risk Linked to Long-Term PM2.5 Exposure[J]. Environmental Health Perspectives, 2012, 120(5): a205.

[7] Pope CA, Burnett RT, Thun MJ, Calle EE, Krewski D, Ito K, Thurston GD (2002) Lung cancer, cardiopulmonary mortality, and longterm exposure to fine particulate air pollution[J]. J Am Med Assoc, 2002, 287(9):11321141.

[8] Reis MA, Carvalho A, Taborda A, Quaresma A, Dias G, Alves LC, Mota M, et al. High airborne PM2.5 chlorine concentrations link to diabetes surge in Portugal[J]. Science of the Total Environment, 2009, 407(21): 57265734 .

[9] Short-term effect of PM2.5 on daily hospital admissions in Madrid (2003-2005)[J]. International Journal of Environmental Health Research, 2010, 20(2): 129-140.

[10] Xiaochuan P, Guoxin L, Ting G. Dangerous Breathing PM2.5 Health Hazard and Economic Loss Assessment [M]. Beijing: China Environmental Science Press, 2013:2-3.

[11] Quan M, Shiqiu Z. Assessment of Direct Socioeconomic Losses in China's Large Haze Events in January 2013 [J]. China Environmental Science, 2013, 33(11):2087-2094.

[12] Yuanbo X, Juan C, Wei L. Assessment of the Health Risk and Damage Value of Persistent Exposure to High Levels of PM2.5 During Heavy Haze Pollution in Beijing Residents [J]. Environmental Science, 2014, 35(1):1-8.

[13] Xiu Teng W, Ya Jing Z, Ling X, Ling L. Economic Analysis of Residents' Health Potential Benefits from PM2.5 Reduction Caused by New Ambient Air Quality Standard in Beijing[J]. Advanced Materials Research, 2012, 524527:3371-3375 